\title{
Synaptic plasticity mechanisms common to learning and alcohol use disorder
}

\author{
David M. Lovinger and Karina P. Abrahao \\ Laboratory for Integrative Neuroscience, Division of Intramural Clinical and Biological Research, National Institute on Alcohol Abuse \\ and Alcoholism, Bethesda, Maryland 20892, USA
}

\begin{abstract}
Alcohol use disorders include drinking problems that span a range from binge drinking to alcohol abuse and dependence. Plastic changes in synaptic efficacy, such as long-term depression and long-term potentiation are widely recognized as mechanisms involved in learning and memory, responses to drugs of abuse, and addiction. In this review, we focus on the effects of chronic ethanol $(\mathrm{EtOH})$ exposure on the induction of synaptic plasticity in different brain regions. We also review findings indicating that synaptic plasticity occurs in vivo during EtOH exposure, with a focus on ex vivo electrophysiological indices of plasticity. Evidence for effects of EtOH-induced or altered synaptic plasticity on learning and memory and EtOH-related behaviors is also reviewed. As this review indicates, there is much work needed to provide more information about the molecular, cellular, circuit, and behavioral consequences of EtOH interactions with synaptic plasticity mechanisms.
\end{abstract}

\section{Different forms of synaptic plasticity}

The most commonly studied forms of synaptic plasticity thought to contribute to learning and memory are long-term depression (LTD) and long-term potentiation (LTP). As the names imply, these changes involve long-lasting decreases and increases in synaptic efficacy, respectively. The mechanisms involved in LTD and LTP have been reviewed extensively, as have their potential roles in addiction (Collingridge et al. 2010; Grueter et al. 2012; Nestler 2013).

\section{LTD measured in vitro}

Different forms of LTD have been described at glutamatergic synapses, involving both pre- and postsynaptic mechanisms (Collingridge et al. 2010). The predominant mechanism underlying presynaptic LTD is decreased probability of neurotransmitter release (Upreti et al. 2013; Atwood et al. 2014b). Activation of a variety of $G$ protein-coupled receptors (GPCRs) that signal through $\mathrm{G}_{\mathrm{i} / \mathrm{o}}$-type $\mathrm{G}$ proteins can induce LTD at synapses throughout the brain (Atwood et al. 2014b).

Among the best-characterized forms of $\mathrm{G}_{\mathrm{i} / \mathrm{o}}$-induced presynaptic LTD is that involving endocannabinoid (eCB) activation of the type 1 cannabinoid receptor (CB1) (Augustin and Lovinger 2018). The eCB-CB1 signaling system is present at a wide variety of synapses throughout the brain, where postsynaptic eCB production and release leads to activation of presynaptic $\mathrm{CB} 1$ receptors to initiate decreased probability of release. The eCB production and release usually involve increases in postsynaptic intracellular calcium and/or activation of $\mathrm{G}_{\mathrm{q}}$-coupled GPCRs (Castillo et al. 2012). In many cases, this synaptic depression outlasts CB1 activation, and this is defined at eCB-LTD (Castillo et al. 2012; Augustin and Lovinger 2018). Other signaling mechanisms have also been reported to produce presynaptic LTD (e.g., nitric oxide) (Upreti et al. 2013). The intra-terminal signaling mechanisms involved in $\mathrm{G}_{\mathrm{i} / \mathrm{o}}$-induced presynaptic LTD expression appear to include decreased cAMP production and PKA activation, as well as protein translation involving presynaptic RNA (Yin et al. 2006; Castillo et al. 2012; Younts et al. 2016).
A widespread mechanism for postsynaptically expressed LTD is decreased function of synaptic AMPA-type glutamate ligandgated ion channel-type receptors (GluAs or AMPARs) (Collingridge et al. 2010). This form of LTD is usually initiated by activation of NMDA-type glutamate receptors (GluNs or NMDARs) or other receptors/ion channels that can produce moderate increases in intracellular calcium concentration (Collingridge et al. 2010). This calcium increase activates intracellular signaling molecules including calmodulin, the calmodulin-activated protein phosphatase calcineurin (aka PP2B), protein phosphatase PP1, other signaling enzymes and receptor-associated proteins leading to reduced AMPAR levels at synapses (Collingridge et al. 2010). Alterations in AMPAR subunit content and decreases in NMDAR function have also been implicated in postsynaptic LTD (Dore et al. 2017). Postsynaptically expressed LTD has been observed in neurons throughout the brain and brainstem.

LTD also occurs at GABAergic synapses (McBain and Kauer 2009). The mechanisms underlying this plasticity involve some that are similar to those implicated in glutamatergic plasticity, but also some divergent intracellular cascades (McBain and Kauer 2009). Studies have shown that hippocampal eCB, $\mathrm{GABA}_{\mathrm{B}}$ and delta-opioid receptors can be involved in GABAergic LTD (for review, see Rozov et al. 2017). Endocannabinoid-dependent presynaptic GABAergic LTD is induced by high or low-frequency repetitive synaptic stimulation (Chevaleyre and Castillo 2003; Zhu and Lovinger 2007), L-type calcium channel activation (Adermark et al. 2009) or theta burst stimulation (Heifets et al. 2008; Jappy et al. 2016).

Postsynaptically expressed LTD also occurs at GABAergic brain synapses, with expression mechanisms that appear to involve decreased synaptic numbers and/or function of $\mathrm{GABA}_{\mathrm{A}^{-}}$ type ligand-gated ion channels (Kullmann and Lamsa 2011; Kodangattil et al. 2013). Theta-burst stimulation induces GABAergic LTD on hippocampal pyramidal neurons, with activation of $\mathrm{GABA}_{\mathrm{B}}$ receptors and suppression of AC/cAMP/PKA activity involved in LTD induction (Jappy et al. 2016). In addition, highfrequency stimulation at GABAergic synapses formed by parvalbumin-expressing interneurons in the hippocampus 
induces LTD that is mediated by delta-opioid, but not mu-opioid, receptors (Piskorowski and Chevaleyre 2013).

\section{LTP measured in vitro}

Presynaptically expressed LTP is less well characterized than other forms of synaptic plasticity. Nonetheless, there is evidence at a number of synapses that long-lasting increases in glutamate release are observed following certain patterns of afferent stimulation or pharmacological treatments (MacDougall and Fine 2014). A variety of different intra-terminal signaling cascades have been implicated in these increases, including increased cAMP/PKA signaling, nitric oxide actions on presynaptic enzymes, changes in presynaptic ion channel function, and increased phosphorylation of proteins involved in vesicle fusion (for review, see Yang and Calakos 2013). Perhaps the best characterized form of presynaptic LTP is observed at the glutamatergic synapses made by mossy fibers on CA3 pyramidal neurons in the hippocampus (Yeckel et al. 1999; Evstratova and Toth 2014). This LTP involves intra-terminal calcium increases, cAMP/PKA signaling and increased vesicle fusion/ glutamate release.

Postsynaptically expressed LTP at glutamatergic synapses was the first type of synaptic plasticity to be discovered (Lomo 2018) and it is the best characterized form of plasticity, expressed in a wide variety of cortical and subcortical neurons. The cellular mechanisms that contribute to LTP are often the opposite of those underlying postsynaptic LTD, in this case involving increased, rather than decreased synaptic AMPAR function (Luscher et al. 2000; Herring and Nicoll 2016). Altered AMPAR subunit composition, sometimes associated with altered AMPAR single channel conductance, also appears to contribute to postsynaptic LTP (Benke et al. 1998; Beaulieu-Laroche and Harnett 2018). There is physiological and pharmacological evidence for transient synaptic expression of calcium-permeable AMPARs that lack GluA2 following LTP induction (Isaac et al. 2007). This transient expression is thought to help consolidate LTP expression. The molecular mechanisms underlying postsynaptic LTP begin with activation of NMDARs leading to relatively large increases in postsynaptic calcium. The calcium increase activates the calcium-calmodulindependent CamKII alpha protein kinase along with protein kinase C (Herring and Nicoll 2016). There is also increased cAMP production leading to activation of protein kinase A (Nguyen and Woo 2003). Activation of these kinases leads to phosphorylation of AMPARs that enhance synaptic localization and alter subunit structure. While alterations in AMPAR phosphorylation are implicated in both postsynaptic LTD (phosphorylation of GluA2, dephosphorylation of GluA1) and postsynaptic LTP (phosphorylation of GluA1), different amino acid residues appear to be involved in the phosphorylation changes that underlie the removal and insertion of receptors that is key to these forms of plasticity (Kessels and Malinow 2009).

LTP can also occur at GABAergic synapses, and both pre- and postsynaptic mechanisms have been implicated in this plasticity (Nugent and Kauer 2008; Maffei 2011). Theta frequency stimulation induces selective LTP of GABA $\mathrm{A}_{\mathrm{A}}$ receptor-mediated synaptic responses that involves activation of $\mathrm{GABA}_{\mathrm{B}}$ and glutamate type I/II metabotropic receptors in hippocampus (Patenaude et al. 2003). GABA neurons in the ventral tegmental area (VTA) and accumbal GABAergic afferents also exhibit LTP after high frequency stimulation (Nugent et al. 2007; Simmons et al. 2017). However, much less is known about GABAergic LTP.

\section{LTD and LTP measured in vivo}

The mechanistic studies characterizing LTD and LTP discussed above were performed using brain slice preparations from various brain regions. However, there is ample evidence that LTD and
LTP can be induced in the in vivo brain, beginning with the first characterization of LTP in the hippocampus (Bliss and Lomo 1973), and LTD in the cerebellum (Ito and Kano 1982), respectively. The reader is referred to studies showing in vivo LTP in different brain regions (Manahan-Vaughan 1997; Poschel and ManahanVaughan 2005; Chu et al. 2014).

\section{Ex vivo indices of LTD and LTP}

There is considerable interest in determining if synaptic plasticity occurs in vivo following environmental events, including learning and memory and exposure to drugs of abuse. Changes in synapse function, neuronal morphology/ultrastructure and molecular/biochemical responses in neurons (e.g., immediate-early gene expression) are involved in synaptic plasticity and have been used as ex vivo proxies for the occurrence of plasticity in vivo. Reviews have provided useful overviews of these approaches, including changes in dendritic spines and immediate early gene expression (Alvarez and Sabatini 2007; Minatohara et al. 2015). LTD and LTP involve changes in receptor expression or function that can be investigated by quantifying the expression levels of these ion channels or by several electrophysiological techniques. In this review we will focus on the electrophysiological indices of synaptic transmission most often used in these studies.

Investigators have used the "AMPA/NMDA ratio" as one index of plasticity, including following exposure to drugs of abuse (Citri and Malenka 2008; Kessels and Malinow 2009). This index is commonly measured by holding the membrane potential at positive potentials (for example, $+40 \mathrm{mV}$ ), to completely relieve the $\mathrm{Mg}^{2+}$ block of NMDARs. A typical procedure is to record a dual component EPSC (mediated by both AMPAR and NMDAR) and then apply an NMDA antagonist to isolate the AMPA EPSC. The NMDA EPSC is obtained by digital subtraction of the AMPA EPSC from the dual component EPSC. Measurement of the AMPA EPSC can also be made at membrane potentials nearer to the resting level. The ratio can only be used to compare different conditions and the relative contributions of AMPA and NMDA receptors. This method can be affected by the adequacy of the neuronal space clamp and also assumes that there is no change in the calcium-impermeable AMPARs as rectification of these receptors can confound the measure (for review, see Kauer and Malenka 2007). Indeed, insertion of calcium-impermeable AMPARs is another index of plasticity and it can be estimated by examining rectification of EPSCs at different voltage-clamp steps and sensitivity to polyamine-based compounds that inhibit GluA2-lacking receptors (Isaac et al. 2007; Kessels and Malinow 2009).

Alterations in synaptic currents that report single-synapse responses have been used to determine the presence and locus of synaptic plasticity. Miniature postsynaptic currents (mPSCs) at GABAergic (mIPSCs) and glutamatergic (mEPSCs) synapses are measured in the absence of action potential firing and report the frequency, amplitude and kinetics of responses at individual synapses. The mPSC frequency generally provides an index of the combined effects of synapse number and probability of release (Kavalali 2015). Additionally, responses to local neurotransmitter application using chemical "uncaging" (Araya 2014) can be used to measure the amplitude and kinetics of single synapse currents, providing information about postsynaptic responsiveness.

Measurement of unitary PSCs induced by stimulation of a single presynaptic neuron (Bolshakov et al. 1997), which is best achieved with paired pre- and postsynaptic recordings are also used to determine the presence of pre- or postsynaptic plasticity. This latter technique allows the investigator to use quantal analysis and estimation of the success or failure to induce a synaptic response (method of failures) to determine probability of release at a single synapse. 
Another related technique takes advantage of the fact that $\mathrm{Sr}^{2+}$ can substitute for $\mathrm{Ca}^{2+}$ in excitation/secretion-coupling, but with lower affinity for the relevant divalent cation binding sites (Oliet et al. 1996). The frequency, amplitude and kinetics of these asynchronous PSCs can then be used as in MPSC measurement to determine if pre- or postsynaptic plasticity has occurred. Using these techniques, investigators have determined if pre- or postsynaptically expressed LTD and LTP occur following in vivo experiences.

The relationship between intraterminal $\mathrm{Ca}^{2+}$ and probability of release leads to changes in responses to paired synaptic stimuli, as residual $\mathrm{Ca}^{2+}$ from the first stimulus will influence release in response to the second stimulus (Zucker and Regehr 2002). In general, an increase in this paired-pulse ratio, deemed paired-pulse facilitation (PPF), indicates decreased probability of release (larger effect of residual $\mathrm{Ca}^{2+}$ if levels are lower after the first pulse). In contrast, paired-pulse depression (PPD) is indicative of increased probability of release. These measures have been used to determine if presynaptically expressed LTD and LTP have occurred in vivo. However, it must be noted that changes in paired-pulse ratio generally occur over a restricted range of baseline probability of release values (Atzori et al. 2001; Zucker and Regehr 2002), and thus this technique has limited sensitivity.

\section{Brief summary of current evidence for roles in learning and memory}

Since the discovery of LTP over $40 \mathrm{yr}$ ago, there has been a longstanding effort to determine if and how synaptic plasticity contributes to learning and memory. This subject has been reviewed extensively in recent years (Collingridge et al. 2010), and thus it will be discussed only briefly at present and the reader is referred to more comprehensive reviews.

Early experiments assayed if changes in synaptic efficacy observed in vivo coincided with learning. Most of these studies focused on the hippocampal formation as LTP was well characterized in that brain region. Evidence that training induces an LTP-like enhancement of synaptic efficacy in vivo has been observed in hippocampus using Pavlovian conditioning (Gruart et al. 2006) and in amygdala using fear conditioning (Rogan et al. 1997). Hippocampal LTD- and depotentiation-like synaptic changes have been reported using novelty detection and Pavlovian conditioning procedures (Manahan-Vaughan and Braunewell 1999; Abraham et al. 2002; Kemp and Manahan-Vaughan 2004; Li et al. 2005; Gruart et al. 2006), and altered hippocampal LTD is associated with stress-induced impairment of spatial memory retrieval (Wong et al. 2007). In the perirhinal cortex, an LTD-like change in synaptic transmission accompanies familiarity discrimination (Brown and Bashir 2002).

Other studies attempted to induce synaptic plasticity in key circuits to determine if these manipulations had effects on learning and memory. In the Barnes and McNaughton laboratories, investigators induced LTP in the dentate gyrus with electrical stimulation of the perforant pathway, and this manipulation produced a deficit in spatial learning and recall of recently acquired, but not previously acquired spatial memories (McNaughton et al. 1986). Disruption of Pavlovian conditioning was observed following strong LTP induction at CA3-CA1 hippocampal synapses (Gruart et al. 2006). This memory disruption has been suggested to involve saturation of the LTP process that prevents further learning-associated increases in synaptic efficacy, although other explanations such as induction of pathological neuronal synchrony have not been ruled out.

Optogenetics has also been used to determine if plasticity induction produces learning and/or memory. Nabavi and coworkers used a fear-conditioning paradigm coupled with optogenetic stim- ulation and found that induction of LTD by low-frequency stimulation of auditory inputs to amygdala inactivated fear memories (Nabavi et al. 2014). Induction of LTP could induce behaviors indicative of reactivation of the fear memory. Interestingly, LTP could not reverse extinction, consistent with the idea that different types of plasticity contribute to this form of learning (Izquierdo et al. 2016).

\section{Alcohol use disorder and memory deficits}

Among the psychiatric disorders, alcohol use disorder (AUD) is one of the leading causes of worldwide deaths, victimizing around 129 thousand people in 2015 (Global Health Estimates 2015: Deaths by Cause, Age, Sex, by Country and by Region, 2000-2015). Furthermore, the prospective epidemiology does not seem very positive, as the 2014 Global Health Observatory data repository (WHO Global Information System on Alcohol and Health) estimates that $14 \%$ of the world's $15-19$-yr-old are drinkers and there is an increasing concern with excessive binge EtOH consumption particularly in this age group.

EtOH exposure triggers cognitive deficits that include mild cognitive impairment, blackouts during strong intoxication (Hermens and Lagopoulos 2018), memory deficits and executive dysfunction in EtOH-dependent individuals (Bates et al. 2002; Pitel et al. 2007; Chen et al. 2018). These changes are associated with neuroadaptations in brain regions implicated in learning and memory including, but not limited to, the amygdala complex, cortex, hippocampus, and striatum (Abrahao et al. 2017). These neuroadaptations also contribute to alterations in the rewarding and aversive effects of ethanol (EtOH), as well as changes in behaviors related to EtOH consumption (Abrahao et al. 2017). Indeed, these behavioral changes involve learning and memory-like processes.

There is growing evidence that prolonged EtOH exposure produces or alters synaptic plasticity (Lovinger and Roberto 2013; Zorumski et al. 2014; Abrahao et al. 2017; Morisot and Ron 2017). This review will describe current evidence for EtOH-induced alterations in the induction of synaptic plasticity in different brain regions. We will also comment on evidence from ex vivo examination of indices that in vivo EtOH exposure induces plasticity. Some discussion of the mechanisms underlying these plasticity changes will also be included. The potential roles that these changes in plasticity play in EtOH-related behaviors and cognitive disruption will be discussed.

\section{Plasticity induced by chronic ethanol exposure or drinking}

Studies examining EtOH effects on synaptic plasticity have been ongoing for decades. There is considerable evidence that acute application of EtOH reduces LTP (Zorumski et al. 2014). Acute EtOH effects on LTD have also been examined in different brain regions (Valenzuela et al. 2010; Zorumski et al. 2014). While these findings are interesting, especially in relation to the cognitive effects of $\mathrm{EtOH}$, this review will focus on chronic effects of the drug that alter synaptic plasticity and ex vivo indices of plasticity.

\section{Alterations in LTD and LTP}

Experiments in which investigators compared induction of LTD and LTP in brain slices from control and chronic EtOH-exposed rodents constituted the bulk of early studies examining effects on glutamatergic and GABAergic synaptic plasticity (McCool 2011; Olsen and Spigelman 2012; Lovinger and Roberto 2013; Zorumski et al. 2014; Abrahao et al. 2017). Here, we pay 
particular attention to the time course of the synaptic plasticity changes during early and protracted withdrawal and the different types of synaptic plasticity. While it is interesting to compare these plasticity changes to those induced by other drugs of abuse, this topic is not the focus of the present review. We refer readers to other outstanding reviews that cover this topic (Hyman et al. 2006; Kauer and Malenka 2007; Luscher and Malenka 2011).

Chronic EtOH exposure impairs LTD in hippocampus (Roberto et al. 2002; Thinschmidt et al. 2003; Coune et al. 2017), dorsal striatum (Cui et al. 2011; DePoy et al. 2013, 2015) the dopamine D1 receptor-containing neurons of the nucleus accumbens (NAc) shell (Jeanes et al. 2011; Spiga et al. 2014; Renteria et al. $2018 \mathrm{~b}$ ) and the NAc core (Abrahao et al. 2013). Both NMDA and CB1-dependent LTD are impaired by chronic EtOH exposure. In addition, recent work observed blunted mGluR5-induced LTD in the hippocampus shortly after cessation of EtOH exposure (Wills et al. 2017). Chronic EtOH exposure also induces loss of CB1dependent presynaptic LTD in the dorsolateral striatum (DLS) (Xia et al. 2006; Adermark et al. 2011; DePoy et al. 2013). At GABAergic synapses, eCB-dependent LTD in striatum is also impaired following chronic EtOH drinking, facilitating a long-lasting potentiation of striatal output in response to glutamatergic transmission (Adermark et al. 2011).

EtOH exposure reversibly inhibits postsynaptically expressed LTP (Roberto et al. 2002) in hippocampus (Durand and Carlen 1984; Thinschmidt et al. 2003; Stephens et al. 2005), basolateral amygdala (BLA) (Stephens et al. 2005), and the bed nucleus of the stria terminalis (Francesconi et al. 2009). Enhanced expression of NMDA-receptor mediated spike-timing-dependent LTP is observed in medial PFC (Kroener et al. 2012), orbitofrontal cortex (OFC) (Nimitvilai et al. 2016), and GluN2B-NMDAR-dependent LTP is enhanced in the DMS (Wang et al. 2012).

The changes in synaptic plasticity induction produced by in vivo EtOH exposure follow different time-courses following with- drawal depending on the brain region as described in the following paragraph and in Figure 1. These changes can result from either a direct inhibition of the induction of plasticity or from occlusion of plasticity induction by plasticity that occurred prior to the recording.

Figure 1 summarizes specific changes in LTP and LTD during early or protracted withdrawal for four brain regions implicated in learning and memory and EtOH-related behaviors. Although deficits in LTD and LTP in hippocampus seem to be stable during early and protracted withdrawal, striatal plasticity deficits often reach their maximum level within $48 \mathrm{~h}$ of the last EtOH exposure (Xia et al. 2006; Wang et al. 2012). In addition, while LTD changes in the NAc shell occur early in EtOH withdrawal (Jeanes et al. 2014; Renteria et al. 2017), LTD alterations in the NAc core occur in late withdrawal (Abrahao et al. 2013; Renteria et al. 2018b), but only in those mice that developed behavioral sensitization (Abrahao et al. 2013). Increased LTP expression occurs in both the lateral orbitofrontal cortex (OFC) (Nimitvilai et al. 2016) and the medial prefrontal cortex (mPFC) (Kroener et al. 2012) following chronic EtOH exposure, but as yet there is little information on the time course of these changes, and the effects of different exposure protocols.

GABAergic synapses also appear to regulate $\mathrm{EtOH}$ effects on cortical plasticity. In humans, very low doses of EtOH (BECs $<5$ $\mathrm{mM}$ ), but not GABAergic hypnotic drugs, suppress LTP-like plasticity, measured by paired associative transcranial magnetic stimulation (PAS-LTP) used in healthy subjects (Lucke et al. 2014). Binge EtOH exposure also impairs PAS-LTP in the motor cortex of EtOH binge drinkers (Loheswaran et al. 2016). In contrast, EtOH enhances PAS-LTD plasticity in human cortex (Fuhl et al. 2015). Both effects may be associated with $\mathrm{EtOH}$ enhancement of extrasynaptic $\mathrm{GABA}_{\mathrm{A}}$ receptor-mediated tonic inhibition. Studies in laboratory animals would be necessary to identify the specific role of GABAergic tonic inhibition in regulating EtOH effects on plasticity at synapses on cortical neurons.

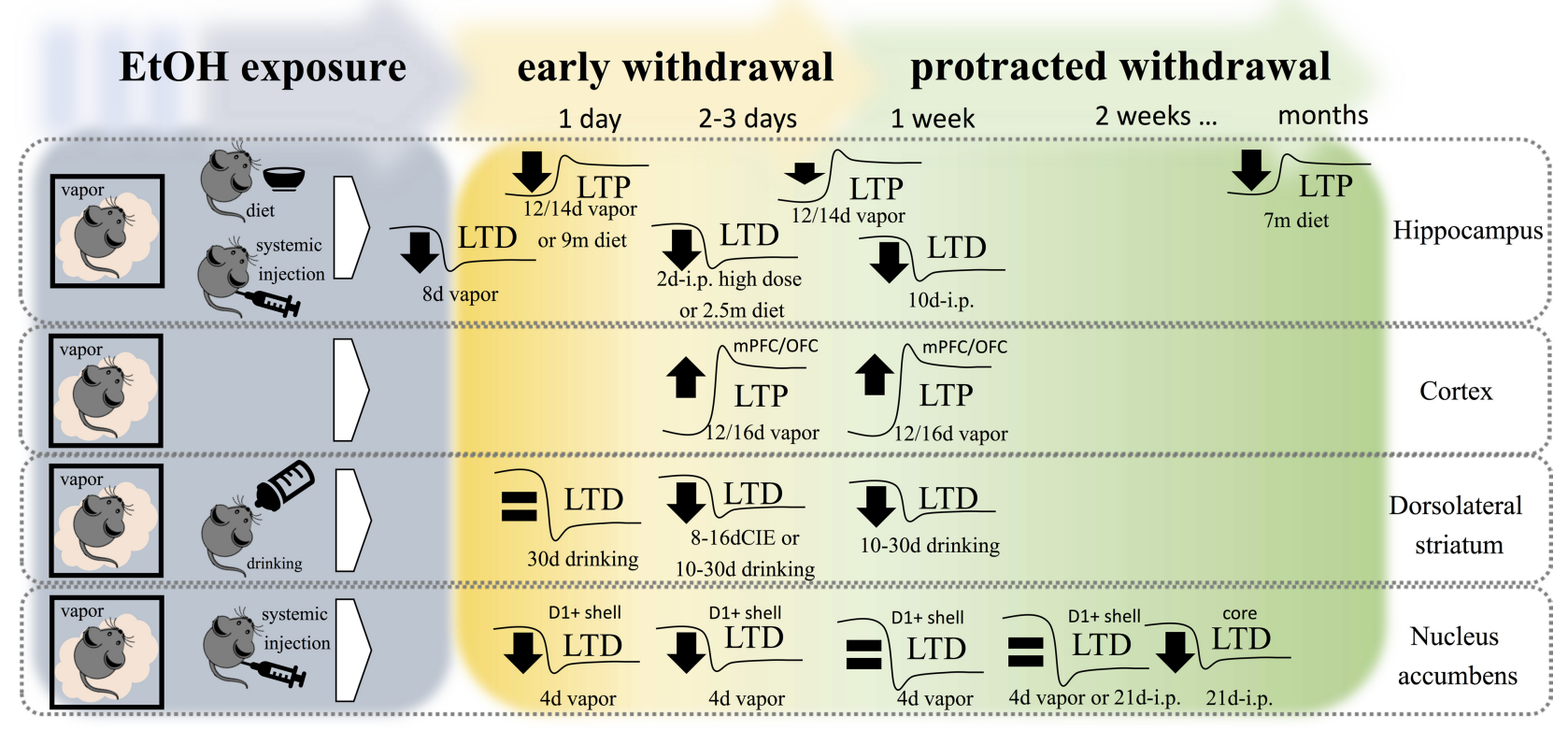

Figure 1. Plasticity changes during withdrawal after chronic ethanol exposure in four brain regions important for learning and memory processes: hippocampus, cortex (medial prefrontal cortex, mPFC, and orbital frontal cortex, OFC), dorsolateral striatum, and nucleus accumbens (shell and core). Experiments used vapor chambers, ethanol liquid diet or systemic injections (intra-peritoneal. i.p.) and measures of long-term depression (LTD) or longterm potential (LTP). The length of ethanol treatment is represented under each plasticity change: $(\mathrm{d})$ days, $(\mathrm{m})$ months. Blue $=\mathrm{EtOH}$ exposure paradigm, yellow = early withdrawal (1-3 d) and in green = protracted withdrawal ( 1 wk up to months). 


\section{Alterations in ex vivo indices of synaptic plasticity}

Several studies have reported evidence of plasticity at GABAergic and glutamatergic synapses after chronic EtOH exposure, and these have been reviewed in depth recently (Lovinger and Kash 2015; Abrahao et al. 2017; Morisot and Ron 2017). Thus, we will focus on those changes that are most indicative of in vivo LTD and LTP.

Increased NMDAR function following chronic EtOH exposure has been observed in several brain regions (Floyd et al. 2003; Carpenter-Hyland and Chandler 2007; Wang et al. 2007, 2011; Morisot and Ron 2017). The increased function of this receptor could set up conditions in which LTP is more readily induced in vivo. In the dorsomedial striatum (DMS) it appears that this sequence of events occurs following EtOH exposure and consumption. The process of increasing NMDAR function begins during acute EtOH exposure. Brain slice recordings in DMS show that application of EtOH inhibits NMDA-EPSCs (Popp et al. 1998; Wang et al. 2007; Yin et al. 2007), as observed in other brain regions (Lovinger et al. 1989). This inhibition is maintained throughout EtOH application, but when $\mathrm{EtOH}$ is washed from the slice the NMDA-EPSC is increased in amplitude above the original pre-EtOH amplitude. This EPSC increase persists for the duration of recordings and thus has been termed long-term facilitation (LTF) (Wang et al. 2007). The mechanisms underlying this LTF process involve Fyn kinase-mediated phosphorylation of the GluN2B NMDA subunit. Enhanced function of GluN2B-containing NMDARs has also been observed in DMS brain slices examined following several days of EtOH exposure or after weeks of voluntary EtOH consumption in an intermittent access paradigm (Wang et al. 2011). The mechanisms underlying this increase appear to be the same as LTF.

The initial LTF observed following acute exposure is not accompanied by any change in AMPA-EPSCs. However, following chronic EtOH consumption or noncontingent in vivo exposure increased AMPA-EPSCs are observed (Wang et al. 2012). Thus, it was proposed that LTF of NMDA-EPSCs induces an LTP-like process that enhances AMPAR function if given enough drug exposure and time in vivo. The enhanced GluN2B-NMDAR function appears to have a role in initiating this LTP-like process. This AMPAfication occurs mainly at glutamatergic synapses onto striatal medium spiny projection neurons (MSNs) that are part of the "direct" striatonigral pathway (Wang et al. 2015). This provides a mechanism through which chronic EtOH enhances striatal output that eventually enhances cortical activation that may favor enhanced drug seeking.

The majority of studies analyzed GluN expression or currents in early withdrawal after chronic EtOH exposure. Protracted withdrawal may modulate glutamate receptors levels differently. One week after the last exposure to EtOH, GluN mRNA levels are decreased in central amygdala, which is accompanied by decreased PPF of NMDA-EPSCs (Roberto et al. 2006). In the NAc, 2 wk of withdrawal from EtOH treatment resulted in less expression of GluN1, but no significant change in the surface expression of GluN2A, GluN2B, or GluA2/3 AMPA channels in the neuronal membrane, which was associated with impaired NMDA-dependent LTD in EtOH-sensitized mice (Abrahao et al. 2013). In PFC, the increased GluN1 and GluN2B expression observed in early withdrawal is not present after $1 \mathrm{wk}$ of withdrawal (Kroener et al. 2012).

There is also evidence for LTP-like alterations at synapses in several other brain regions based on increases in AMPAR function and changes in AMPA/NMDA ratios and rectification of AMPA-EPSCs. Analysis of glutamatergic transmission in VTA dopaminergic neurons revealed evidence of increased postsynaptic AMPAR function during a short (12-24 h) withdrawal period fol- lowing weeks of intermittent EtOH drinking (Stuber et al. 2008). While the increased AMPA/NMDA ratio observed in this study does not provide definitive evidence of increased AMPAR function, this conclusion was supported by increased amplitude of AMPARmediated mEPSCs, with no change in paired-pulse facilitation. Increased AMPAR-mediated glutamatergic synaptic responses are observed in NAc MSNs following weeks of EtOH exposure via gavage (Marty and Spigelman 2012). A similar increase in AMPAR-mediated glutamatergic transmission was observed in periaqueductal gray neurons after withdrawal following $4 \mathrm{~d}$ of $\mathrm{EtOH}$ exposure in a paradigm that fosters withdrawal seizures (Long et al. 2007).

Biochemical studies have revealed ample evidence of increased AMPAR subunit expression in different brain regions following chronic EtOH exposure (for reviews, see Holmes et al. 2013; Hwa et al. 2017), although some studies found no changes in hippocampus (Ferreira et al. 2001; Puglia and Valenzuela 2010). A recent study indicates that $\mathrm{EtOH}$ increases the rectification of AMPAR-mediated EPSCs in NAc MSNs, a change generally associated with increased expression of receptors lacking the GluA2 subunit (Laguesse et al. 2017). The intracellular signaling pathway implicated in this synaptic plasticity involves Prosapip1-dependent postsynaptic protein interactions and signaling through the mammalian target of rapamycin complex (Laguesse et al. 2017). This study also provides evidence that this signaling pathway can regulate EtOH reward, seeking, and drinking.

There is also evidence of presynaptic glutamatergic plasticity following chronic EtOH exposure or drinking (for review, see Lovinger 2017). In rat BLA principal neurons paired pulsefacilitation of EPSCs was decreased and frequency of mEPSCs increased following chronic intermittent EtOH exposure and withdrawal (Lack et al. 2007). A similar decrease in paired pulse-ratio of EPSCs was observed in GABAergic neurons of the CeA in one study (Zhu et al. 2007), but not in another (Roberto et al. 2004b). Increased mEPSC frequency was also observed in serotonergic neurons of the dorsal raphe nucleus (Lowery-Gionta et al. 2015). In the monkey putamen, mEPSC frequency is increased following longterm EtOH consumption interspersed with periods of forced abstinence, and this physiological change is accompanied by increased dendritic spine density on putamen MSNs (Cuzon Carlson et al. 2011). Thus, chronic EtOH appears to produce a presynaptic LTP-like change at glutamatergic synapses in several brain regions, but it is not yet clear if this involves increased probability of release, increased synaptic numbers, or both.

There is much less information about chronic EtOH effects on GABAergic transmission that is indicative of in vivo plasticity, but in general the findings provide evidence of presynaptic LTD-like changes following chronic exposure or drinking. Increased pairedpulse facilitation was observed at GABAergic synapses of lateral/ paracapsular neurons onto principal neurons in the BLA following chronic EtOH exposure (Diaz et al. 2011). Interestingly, synapses made by local interneurons were not affected by this treatment (Diaz et al. 2011). A similar paired-pulse facilitation increase was observed at GABAergic synapses in dentate gyrus granule neurons from monkeys that consumed EtOH for 18 mo (Ariwodola et al. 2003). In rat hippocampal CA1 pyramidal neurons, the frequency of mIPSCs was decreased following chronic intermittent EtOH exposure (Cagetti et al. 2003). Decreased mIPSC frequency is observed when recording from MSNs in the mouse DLS and DMS and monkey caudate and putamen following chronic EtOH consumption (Cuzon Carlson et al. 2011, 2018; Wilcox et al. 2014). These findings indicate that several GABAergic synapses show decreased probability of release or numbers of synapses following chronic EtOH exposure or drinking. One exception is synapses in the $\mathrm{CeA}$ that show decreased paired-pulse ratios and increased mIPSC frequency in EtOH-dependent rats (Roberto et al. 2004a). 
Changes in $\mathrm{GABA}_{\mathrm{A}}$ receptor subunit expression and some evidence of changes in postsynaptic receptor function have also been observed following chronic exposure or drinking, and these findings have been nicely summarized in recent reviews (Lovinger and Roberto 2013; Roberto and Varodayan 2017). These postsynaptic changes could signal LTD or LTP-like changes at GABAergic synapses in several brain regions.

Researchers are now using optogenetic tools to identify specific synapses that are affected by EtOH. For example, excessive EtOH intake potentiates AMPA- and NMDA-mediated synaptic transmission at the medial PFC input and increases the probability of glutamate release at the basal lateral amygdala (BLA) afferents to the DMS (Ma et al. 2017). These changes could explain the effect of chronic EtOH exposure on striatal LTP, as paired activation of the medial PFC and BLA inputs using dual-channel optogenetics induced robust LTP of the corticostriatal input to the DMS (Ma et al. 2017).

The idea that synaptic efficacy is adjusted to maintain an optimal level for proper neuronal and circuit function (Hengen et al. 2013; Keck et al. 2013) fostered research on plasticity mechanisms involved in this process. These forms of plasticity are termed homeostatic synaptic plasticity (HSP) (Turrigiano 2012). Experimental evidence for HSP comes from studies in which strong perturbations of neuronal or synaptic function such as blockade of neuronal firing or ionotropic receptors are applied to neurons (often primary cultures) for days. These treatments generally elicit changes in synaptic efficacy that are opposite to those produced by the treatment itself (e.g., increased synaptic AMPAR function following chronic TTX treatment) (Turrigiano 2012). While these studies are instructive, this concept is nothing new in the drug abuse research field. There has been ample evidence for some time that drugs of abuse produce homeostatic changes in synaptic transmission that compensate for changes in synaptic function or altered circuit function.

In the case of EtOH, the most obvious examples of homeostatic changes in transmission are the increases in NMDAR, and especially GluN2B-containing NMDAR activity following chronic exposure, as discussed earlier in this review (for reviews, see Carpenter-Hyland and Chandler 2007; Morisot and Ron 2017). This increased activity is presumably triggered by acute EtOH inhibition of NMDARs, and we have already discussed how activation of protein kinases and phosphorylation of GluN2B is involved in this plasticity (Wang et al. 2007).

Compensatory changes in GABAergic transmission are also observed following chronic EtOH exposure at synapses where acute exposure increases GABAergic transmission. Potentiation by acute EtOH can involve increases in firing of GABAergic neurons, increased GABA release from terminals or increased $\mathrm{GABA}_{\mathrm{A}} \mathrm{R}$ function (for reviews, see Abrahao et al. 2017; Roberto and Varodayan 2017). Homeostatic compensation usually involves decreased $\mathrm{GABA}_{\mathrm{A}} \mathrm{R}$ function with changes in expression of specific receptor subunits.

There is less information about how synaptic efficacy changes in response to EtOH effects alter excitability within microcircuits or circuits. Exposure to EtOH or NMDAR antagonists induces enlargement of dendritic spines in hippocampal neurons in culture (Carpenter-Hyland and Chandler 2006). Changes in expression and function of calcium-activated potassium channels also appear to compensate for EtOH effects on neuronal function in the hippocampus and VTA (for review, see Mulholland et al. 2009).

Many of the molecular and synaptic changes induced by chronic EtOH exposure would tend to restore levels of synaptic, neuronal, and circuit function to predrug exposure levels when the drug itself is present (e.g., increased glutamatergic transmission that compensates for NMDAR inhibition). However, when EtOH is removed during forced or voluntary abstinence these homeostatic changes can drive neuronal and circuit function to levels higher or lower than those observed prior to drug exposure. Thus, what is initially homeostatic may well become pathological, especially following the sort of repeated withdrawal episodes characteristic of AUD.

\section{Possible roles in Alcohol Use Disorders}

Ultimately, it will be crucial to understand how the plastic changes at synapses in different brain regions contribute to alterations in learning and memory and EtOH-related behaviors. Most studies have focused on examining different subregions of the striatum and the afferents that innervate these areas.

The NAc has well characterized roles in reward-driven behavior, cue-driven drug self-administration, and a variety of drugrelated associative learning processes including conditioned place preference and sensitization (McBride et al. 1999; Gardner 2011; Camarini and Pautassi 2016; Scofield et al. 2016). The Prosapip-1-dependent changes in AMPAR-mediated synaptic transmission in NAc appear to play a role in controlling EtOH selfadministration (Laguesse et al. 2017). LTD impairment in the accumbens core is also associated with behavioral sensitization: while blunted NMDA dependent accumbal LTD is associated with the development of sensitization (Abrahao et al. 2013), blunted hippocampal LTD is observed only in sensitization-resistant mice (Coune et al. 2017).

Plasticity within the dorsal striatum appears to be implicated in control of EtOH seeking and drinking, and also in cognitive and behavioral consequences of chronic exposure to the drug (Corbit et al. 2012; Gremel and Lovinger 2017). Potentiation of glutamatergic synapses onto direct-pathway MSNs in the DMS appears to play an important role in driving goal-directed $\mathrm{EtOH}$ drinking. Injection of Fyn kinase or Glun2B-NMDA antagonists into DMS reduces EtOH seeking and drinking in an operant paradigm in which these processes are driven by goal-directed strategies (Wang et al. 2010). Intra-DMS injection of AMPAR and D1 dopamine receptor antagonists have similar effects (Wang et al. 2012, 2015). Overall, these findings indicate that an LTP-like process that enhances output from the DMS direct pathway is an important step in the development of goal-directed EtOH seeking and drinking.

Recent evidence indicates that in vivo induction of LTD and LTP in mice after exposure to EtOH can modulate EtOH-seeking behavior (Ma et al. 2018). This work showed that application of an LTP-inducing protocol in the DMS caused a long-lasting increase in EtOH-seeking behavior, while the LTD protocol decreased this behavior in mice previously exposed to $\mathrm{EtOH}$ (Ma et al. 2018). Additional studies of this type will be useful in determining if and how plasticity in different brain regions can alter EtOH-related behaviors. With the increasing application of optogenetic techniques, these studies can target specific afferent inputs to brain regions of interest.

EtOH seeking and drinking can also involve non-goal-directed/habitual aspects depending on the circumstances of drug exposure (Corbit et al. 2012; O'Tousa and Grahame 2014). The DLS has important roles in control of habitual and inflexible behaviors (Yin and Knowlton 2006). There is growing evidence that chronic EtOH exposure enhances habit learning (Corbit et al. 2012; Renteria et al. 2018a), and other behaviors that involve the DLS, and altered LTD in DLS appears to be involved in these behavioral changes (DePoy et al. 2013).

Studies have related plastic changes in synaptic transmission within the amygdala to changes in anxiety and rewarding drug effects following chronic EtOH exposure. The pre- and postsynaptic changes in AMPAR-mediated glutamatergic synaptic responses in the BLA appear to have roles in the anxiogenic behavior observed 
during withdrawal (Lack et al. 2007). Extinction of conditioned fear responses is another behavior that is altered by chronic EtOH exposure (Tipps et al. 2014; Butler et al. 2016), and altered NMDAR-dependent synaptic plasticity at PFC-BLA synapses appears to have a role in this learning alteration (Holmes et al. 2012). Conditioned place preference for EtOH appears to involve changes in AMPAR-mediated synaptic transmission in the CeA (Zhu et al. 2007).

\section{Future directions}

Ultimately, we hope to make the case that additional work is needed to establish the mechanisms underlying EtOH effects on synaptic plasticity. In the following paragraphs, we suggest a few general directions for future research in addition to the more specific ideas presented earlier in this review.

It has been hypothesized that different drugs of abuse induce similar deficits in synaptic plasticity in the reward system (Luscher and Malenka 2011; Mameli and Luscher 2011). Indeed, investigators have reported similarities in psychostimulant- opioid- and EtOH-induced deficits in plasticity (Korpi et al. 2015), especially changes in AMPA/NMDA ratio after short-term withdrawal (Luscher and Malenka 2011). However, there are particular effects of each drug of abuse, including primary molecular targets, time courses of drug action and withdrawal, and circuit/behavioral changes produced by the different drugs that must be taken into account to better understand how altered synaptic plasticity contributes to use disorders for the different drugs. For example, loss of endocannabinoid-dependent LTD is observed following exposure to several drugs in addition to ethanol (Mato et al. 2005; Xia et al. 2006; Adermark et al. 2011; Atwood et al. 2014a). However, the mechanisms underlying these effects are likely to be different, as cannabinoid drugs down-regulate receptor function, while EtOH may have a more general effect on intraterminal signaling mechanisms involved in presynaptic LTD (Hoffman et al. 2003; Mato et al. 2005; Lovinger 2017). Given the different primary molecular targets of ethanol and other drugs of abuse, it is likely that compensatory plasticity involving changes in these target molecules would also differ for the different substances. Acute ethanol-induced increases in GABA release are often followed by decreased release after chronic exposure as discussed earlier in this review, and these effects may differ with drugs that do not directly target presynaptic GABAergic terminals. Chronic cocaine administration produces changes in GABAergic transmission in the ventral pallidum and VTA (Bocklisch et al. 2013; Kupchik et al. 2014) but as yet there is no direct comparison to EtOH effects in these regions. For these reasons, the alcohol research field should not only look for effects that are similar to and different from those of other drugs of abuse, but also develop new strategies to understand the sequence of neuroadaptations following acute and chronic EtOH exposure and withdrawal.

More attention should be given to different withdrawal time points after EtOH exposure. As observed in Figure 1, deficits in plasticity in the striatal regions and hippocampus can change with time after the last ethanol exposure. Much less is known in the cortex and other brain regions. It is postulated, for example, that withdrawal-dependent plasticity leads to incubation of psychostimulant craving/relapse (summarized in Dong et al. 2017), but similar data are lacking for EtOH. A comprehensive understanding of the dynamic changes in plasticity during withdrawal following EtOH exposure is necessary to better investigate molecular targets potentially important for the treatment of craving and relapse. It is also important to investigate different types of plasticity as they may have different functions in the behavioral effects of $\mathrm{EtOH}$.
We also consider very important that future studies examine how, where and when GABAergic plasticity occurs and how these synaptic changes interact with glutamatergic plasticity. The effect of EtOH on the GABAergic system involves changes in neurotransmitter release, GABA receptor function and GABAergic neuron intrinsic excitability (for review, see Abrahao et al. 2017). Furthermore, there is a large literature indicating that ethanol effects on GABAergic synaptic transmission are involved in the behavioral actions of the drug (for review, see Abrahao et al. 2017). However, much less is understood about how EtOH can interfere with plasticity at GABAergic synapses.

While the findings described in this review represent a good start, more work is clearly needed to understand the many ways in which synaptic plasticity contributes to the cognitive and addictive effects of EtOH.

\section{Acknowledgments}

We acknowledge the support of the Division of Intramural Clinical and Biological Research of the National Institute on Alcohol Abuse and Alcoholism. K.P.A. was also supported by the 2014 IBRO John G. Nicholls Research Fellowship and the Ciências sem Fronteiras program (Coordenadoria de Aperfeiçoamento de Pessoal de Nível Superior-CAPES 2496/13-5, Brazil).

\section{References}

Abraham WC, Logan B, Greenwood JM, Dragunow M. 2002. Induction and experience-dependent consolidation of stable long-term potentiation lasting months in the hippocampus. J Neurosci 22: 9626-9634.

Abrahao KP, Ariwodola OJ, Butler TR, Rau AR, Skelly MJ, Carter E, Alexander NP, McCool BA, Souza-Formigoni ML, Weiner JL. 2013. Locomotor sensitization to ethanol impairs NMDA receptor-dependent synaptic plasticity in the nucleus accumbens and increases ethanol self-administration. J Neurosci 33: 4834-4842.

Abrahao KP, Salinas AG, Lovinger DM. 2017. Alcohol and the brain: neuronal molecular targets, synapses, and circuits. Neuron 96: 1223-1238.

Adermark L, Talani G, Lovinger DM. 2009. Endocannabinoid-dependent plasticity at GABAergic and glutamatergic synapses in the striatum is regulated by synaptic activity. Eur J Neurosci 29: 32-41.

Adermark L, Jonsson S, Ericson M, Soderpalm B. 2011. Intermittent ethanol consumption depresses endocannabinoid-signaling in the dorsolateral striatum of rat. Neuropharmacology 61: 1160-1165.

Alvarez VA, Sabatini BL. 2007. Anatomical and physiological plasticity of dendritic spines. Annu Rev Neurosci 30: 79-97.

Araya R. 2014. Input transformation by dendritic spines of pyramidal neurons. Front Neuroanat 8: 141

Ariwodola OJ, Crowder TL, Grant KA, Daunais JB, Friedman DP, Weiner JL. 2003. Ethanol modulation of excitatory and inhibitory synaptic transmission in rat and monkey dentate granule neurons. Alcohol Clin Exp Res 27: 1632-1639.

Atwood BK, Kupferschmidt DA, Lovinger DM. 2014a. Opioids induce dissociable forms of long-term depression of excitatory inputs to the dorsal striatum. Nat Neurosci 17: 540-548.

Atwood BK, Lovinger DM, Mathur BN. 2014b. Presynaptic long-term depression mediated by $\mathrm{G}_{\mathrm{i} / \mathrm{o}}$-coupled receptors. Trends Neurosci 37: 663-673.

Atzori M, Lei S, Evans DI, Kanold PO, Phillips-Tansey E, McIntyre O, McBain CJ. 2001. Differential synaptic processing separates stationary from transient inputs to the auditory cortex. Nat Neurosci 4: 1230-1237. Augustin SM, Lovinger DM. 2018. Functional relevance of endocannabinoid-dependent synaptic plasticity in the central nervous system. ACS Chem Neurosci. doi: 10.1021/acschemneuro.7b00508

Bates ME, Bowden SC, Barry D. 2002. Neurocognitive impairment associated with alcohol use disorders: implications for treatment. Exp Clin Psychopharmacol 10: 193-212.

Beaulieu-Laroche L, Harnett MT. 2018. Dendritic spines prevent synaptic voltage clamp. Neuron 97: 75-82 e73.

Benke TA, Luthi A, Isaac JT, Collingridge GL. 1998. Modulation of AMPA receptor unitary conductance by synaptic activity. Nature 393: 793-797.

Bliss TV, Lomo T. 1973. Long-lasting potentiation of synaptic transmission in the dentate area of the anaesthetized rabbit following stimulation of the perforant path. J Physiol 232: 331-356. 
Bocklisch C, Pascoli V, Wong JC, House DR, Yvon C, de Roo M, Tan KR, Luscher C. 2013. Cocaine disinhibits dopamine neurons by potentiation of GABA transmission in the ventral tegmental area. Science 341: $1521-1525$.

Bolshakov VY, Golan H, Kandel ER, Siegelbaum SA. 1997. Recruitment of new sites of synaptic transmission during the cAMP-dependent late phase of LTP at CA3-CA1 synapses in the hippocampus. Neuron 19: 635-651.

Brown MW, Bashir ZI. 2002. Evidence concerning how neurons of the perirhinal cortex may effect familiarity discrimination. Philos Trans $R$ Soc Lond B Biol Sci 357: 1083-1095.

Butler TR, Karkhanis AN, Jones SR, Weiner JL. 2016. Adolescent social isolation as a model of heightened vulnerability to comorbid alcoholism and anxiety disorders. Alcohol Clin Exp Res 40: 1202-1214.

Cagetti E, Liang J, Spigelman I, Olsen RW. 2003. Withdrawal from chronic intermittent ethanol treatment changes subunit composition, reduces synaptic function, and decreases behavioral responses to positive allosteric modulators of GABAA receptors. Mol Pharmacol 63: 53-64.

Camarini R, Pautassi RM. 2016. Behavioral sensitization to ethanol: neural basis and factors that influence its acquisition and expression. Brain Res Bull 125: $53-78$.

Carpenter-Hyland EP, Chandler LJ. 2006. Homeostatic plasticity during alcohol exposure promotes enlargement of dendritic spines. Eur J Neurosci 24: 3496-3506.

Carpenter-Hyland EP, Chandler LJ. 2007. Adaptive plasticity of NMDA receptors and dendritic spines: implications for enhanced vulnerability of the adolescent brain to alcohol addiction. Pharmacol Biochem Behav 86: $200-208$

Castillo PE, Younts TJ, Chavez AE, Hashimotodani Y. 2012. Endocannabinoid signaling and synaptic function. Neuron 76: 70-81.

Chen YL, Yang CY, Chen SJ, Chen YC, Su CY. 2018. Everyday memory problems in alcohol abuse and dependence: frequency, patterns and patient-proxy agreement. Psychiatry Res 261: 488-497.

Chevaleyre V, Castillo PE. 2003. Heterosynaptic LTD of hippocampal GABAergic synapses: a novel role of endocannabinoids in regulating excitability. Neuron 38: 461-472.

Chu CP, Zhao GY, Jin R, Zhao SN, Sun L, Qiu DL. 2014. Properties of $4 \mathrm{~Hz}$ stimulation-induced parallel fiber-Purkinje cell presynaptic long-term plasticity in mouse cerebellar cortex in vivo. Eur J Neurosci 39: 1624-1631.

Citri A, Malenka RC. 2008. Synaptic plasticity: multiple forms, functions, and mechanisms. Neuropsychopharmacology 33: 18-41.

Collingridge GL, Peineau S, Howland JG, Wang YT. 2010. Long-term depression in the CNS. Nat Rev Neurosci 11: 459-473.

Corbit LH, Nie H, Janak PH. 2012. Habitual alcohol seeking: time course and the contribution of subregions of the dorsal striatum. Biol Psychiatry 72: 389-395.

Coune F, Silvestre de Ferron B, González-Marín MC, Antol J, Naassila M, Pierrefiche O. 2017. Resistance to ethanol sensitization is associated with a loss of synaptic plasticity in the hippocampus. Synapse 71. doi: $10.1002 /$ syn.21899

Cui SZ, Wang SJ, Li J, Xie GQ, Zhou R, Chen L, Yuan XR. 2011. Alteration of synaptic plasticity in rat dorsal striatum induced by chronic ethanol intake and withdrawal via ERK pathway. Acta Pharmacol Sin 32: $175-181$.

Cuzon Carlson VC, Seabold GK, Helms CM, Garg N, Odagiri M, Rau AR, Daunais J, Alvarez VA, Lovinger DM, Grant KA. 2011. Synaptic and morphological neuroadaptations in the putamen associated with long-term, relapsing alcohol drinking in primates. Neuropsychopharmacology 36: 2513-2528.

Cuzon Carlson VC, Grant KA, Lovinger DM. 2018. Synaptic adaptations to chronic ethanol intake in male rhesus monkey dorsal striatum depend on age of drinking onset. Neuropharmacology 131: 128-142.

DePoy L, Daut R, Brigman JL, MacPherson K, Crowley N, Gunduz-Cinar O, Pickens CL, Cinar R, Saksida LM, Kunos G, et al. 2013. Chronic alcohol produces neuroadaptations to prime dorsal striatal learning. Proc Natl Acad Sci 110: 14783-14788.

DePoy L, Daut R, Wright T, Camp M, Crowley N, Noronha B, Lovinger D, Holmes A. 2015. Chronic alcohol alters rewarded behaviors and striatal plasticity. Addict Biol 20: 345-348.

Diaz MR, Christian DT, Anderson NJ, McCool BA. 2011. Chronic ethanol and withdrawal differentially modulate lateral/basolateral amygdala paracapsular and local GABAergic synapses. J Pharmacol Exp Ther 337: 162-170.

Dong Y, Taylor JR, Wolf ME, Shaham Y. 2017. Circuit and synaptic plasticity mechanisms of drug relapse. J Neurosci 37: 10867-10876.

Dore K, Stein IS, Brock JA, Castillo PE, Zito K, Sjostrom PJ. 2017. Unconventional NMDA receptor signaling. J Neurosci 37: 10800-10807.

Durand D, Carlen PL. 1984. Impairment of long-term potentiation in rat hippocampus following chronic ethanol treatment. Brain Res 308: 325-332.
Evstratova A, Toth K. 2014. Information processing and synaptic plasticity at hippocampal mossy fiber terminals. Front Cell Neurosci 8: 28.

Ferreira VM, Frausto S, Browning MD, Savage DD, Morato Gs, Valenzuela CF. 2001. Ionotropic glutamate receptor subunit expression in the rat hippocampus: lack of an effect of a long-term ethanol exposure paradigm. Alcohol Clin Exp Res 25: 1536-1541.

Floyd DW, Jung KY, McCool BA. 2003. Chronic ethanol ingestion facilitates $\mathrm{N}$-methyl-D-aspartate receptor function and expression in rat lateral/ basolateral amygdala neurons. J Pharmacol Exp Ther 307: 1020-1029.

Francesconi W, Berton F, Repunte-Canonigo V, Hagihara K, Thurbon D, Lekic D, Specio SE, Greenwell TN, Chen SA, Rice KC, et al. 2009. Protracted withdrawal from alcohol and drugs of abuse impairs long-term potentiation of intrinsic excitability in the juxtacapsular bed nucleus of the stria terminalis. J Neurosci 29: $5389-5401$.

Fuhl A, Muller-Dahlhaus F, Lucke C, Toennes SW, Ziemann U. 2015. Low doses of ethanol enhance LTD-like plasticity in human motor cortex. Neuropsychopharmacology 40: 2969-2980.

Gardner EL. 2011. Addiction and brain reward and antireward pathways. Adv Psychosom Med 30: 22-60.

Gremel CM, Lovinger DM. 2017. Associative and sensorimotor cortico-basal ganglia circuit roles in effects of abused drugs. Genes Brain Behav 16: 71-85.

Gruart A, Munoz MD, Delgado-Garcia JM. 2006. Involvement of the CA3-CA1 synapse in the acquisition of associative learning in behaving mice. J Neurosci 26: 1077-1087.

Grueter BA, Rothwell PE, Malenka RC. 2012. Integrating synaptic plasticity and striatal circuit function in addiction. Curr Opin Neurobiol 22: $545-551$.

Heifets BD, Chevaleyre V, Castillo PE. 2008. Interneuron activity controls endocannabinoid-mediated presynaptic plasticity through calcineurin. Proc Natl Acad Sci 105: 10250-10255.

Hengen KB, Lambo ME, Van Hooser SD, Katz DB, Turrigiano GG. 2013. Firing rate homeostasis in visual cortex of freely behaving rodents. Neuron 80: $335-342$.

Hermens DF, Lagopoulos J. 2018. Binge drinking and the young brain: a mini review of the neurobiological underpinnings of alcohol-induced blackout. Front Psychol 9: 12.

Herring BE, Nicoll RA. 2016. Long-term potentiation: from CaMKII to AMPA receptor trafficking. Annu Rev Physiol 78: 351-365.

Hoffman AF, Oz M, Caulder T, Lupica CR. 2003. Functional tolerance and blockade of long-term depression at synapses in the nucleus accumbens after chronic cannabinoid exposure. J Neurosci 23: 4815-4820.

Holmes A, Fitzgerald PJ, MacPherson KP, DeBrouse L, Colacicco G, Flynn SM, Masneuf S, Pleil KE, Li C, Marcinkiewcz CA, et al. 2012. Chronic alcohol remodels prefrontal neurons and disrupts NMDAR-mediated fear extinction encoding. Nat Neurosci 15: $1359-1361$.

Holmes A, Spanagel R, Krystal JH. 2013. Glutamatergic targets for new alcohol medications. Psychopharmacology (Berl) 229: 539-554.

Hwa L, Besheer J, Kash T. 2017. Glutamate plasticity woven through the progression to alcohol use disorder: a multi-circuit perspective. F1000Res 6: 298.

Hyman SE, Malenka RC, Nestler EJ. 2006. Neural mechanisms of addiction: the role of reward-related learning and memory. Annu Rev Neurosci 29: 565-598.

Isaac JT, Ashby MC, McBain CJ. 2007. The role of the GluR2 subunit in AMPA receptor function and synaptic plasticity. Neuron 54: 859-871.

Ito M, Kano M. 1982. Long-lasting depression of parallel fiber-Purkinje cell transmission induced by conjunctive stimulation of parallel fibers and climbing fibers in the cerebellar cortex. Neurosci Lett 33: 253-258.

Izquierdo I, Furini CR, Myskiw JC. 2016. Fear memory. Physiol Rev 96: 695-750.

Jappy D, Valiullina F, Draguhn A, Rozov A. 2016. GABABR-dependent long-term depression at hippocampal synapses between CB1-positive interneurons and CA1 pyramidal cells. Front Cell Neurosci 10: 4.

Jeanes ZM, Buske TR, Morrisett RA. 2011. In vivo chronic intermitten ethanol exposure reverses the polarity of synaptic plasticity in the nucleus accumbens shell. J Pharmacol Exp Ther 336: 155-164.

Jeanes ZM, Buske TR, Morrisett RA. 2014. Cell type-specific synaptic encoding of ethanol exposure in the nucleus accumbens shell. Neuroscience 277: 184-195.

Kauer JA, Malenka RC. 2007. Synaptic plasticity and addiction. Nat Rev Neurosci 8: 844-858.

Kavalali ET. 2015. The mechanisms and functions of spontaneous neurotransmitter release. Nat Rev Neurosci 16: 5-16.

Keck T, Keller GB, Jacobsen RI, Eysel UT, Bonhoeffer T, Hubener M. 2013. Synaptic scaling and homeostatic plasticity in the mouse visual cortex in vivo. Neuron 80: $327-334$.

Kemp A, Manahan-Vaughan D. 2004. Hippocampal long-term depression and long-term potentiation encode different aspects of novelty acquisition. Proc Natl Acad Sci 101: 8192-8197. 
Kessels HW, Malinow R. 2009. Synaptic AMPA receptor plasticity and behavior. Neuron 61: 340-350.

Kodangattil JN, Dacher M, Authement ME, Nugent FS. 2013. Spike timing-dependent plasticity at GABAergic synapses in the ventral tegmental area. J Physiol 591: 4699-4710.

Korpi ER, den Hollander B, Farooq U, Vashchinkina E, Rajkumar R, Nutt DJ, Hyytia P, Dawe GS. 2015. Mechanisms of action and persistent neuroplasticity by drugs of abuse. Pharmacol Rev 67: 872-1004.

Kroener S, Mulholland PJ, New NN, Gass JT, Becker HC, Chandler LJ. 2012. Chronic alcohol exposure alters behavioral and synaptic plasticity of the rodent prefrontal cortex. PLoS One 7: e37541.

Kullmann DM, Lamsa KP. 2011. LTP and LTD in cortical GABAergic interneurons: emerging rules and roles. Neuropharmacology 60: 712-719.

Kupchik YM, Scofield MD, Rice KC, Cheng K, Roques BP, Kalivas PW. 2014. Cocaine dysregulates opioid gating of GABA neurotransmission in the ventral pallidum. J Neurosci 34: 1057-1066.

Lack AK, Diaz MR, Chappell A, DuBois DW, McCool BA. 2007. Chronic ethanol and withdrawal differentially modulate pre- and postsynaptic function at glutamatergic synapses in rat basolateral amygdala. $J$ Neurophysiol 98: 3185-3196.

Laguesse S, Morisot N, Shin JH, Liu F, Adrover MF, Sakhai SA, Lopez MF, Phamluong K, Griffin WC III, Becker HC, et al. 2017. Prosapip1-dependent synaptic adaptations in the nucleus accumbens drive alcohol intake, seeking, and reward. Neuron 96: 145-159 e148.

Li Z, Zhou Q, Li L, Mao R, Wang M, Peng W, Dong Z, Xu L, Cao J. 2005. Effects of unconditioned and conditioned aversive stimuli in an intense fear conditioning paradigm on synaptic plasticity in the hippocampal CA1 area in vivo. Hippocampus 15: 815-824.

Loheswaran G, Barr MS, Rajji TK, Blumberger DM, Le Foll B, Daskalakis ZJ 2016. Alcohol intoxication by binge drinking impairs neuroplasticity. Brain Stimul 9: 27-32.

Lomo T. 2018. Discovering long-term potentiation (LTP)—recollections and reflections on what came after. Acta Physiol (Oxf) 222. doi: 10.1111/ apha. 12921

Long C, Yang L, Faingold CL, Steven Evans M. 2007. Excitatory amino acid receptor-mediated responses in periaqueductal gray neurons are increased during ethanol withdrawal. Neuropharmacology 52: 802-811.

Lovinger DM. 2017. Presynaptic ethanol actions: potential roles in ethanol seeking. Handb Exp Pharmacol. doi: 10.1007/164_2017_76

Lovinger DM, Kash TL. 2015. Mechanisms of neuroplasticity and ethanol's effects on plasticity in the striatum and bed nucleus of the stria terminalis. Alcohol Res 37: 109-124.

Lovinger DM, Roberto M. 2013. Synaptic effects induced by alcohol. Curr Top Behav Neurosci 13: 31-86.

Lovinger DM, White G, Weight FF. 1989. Ethanol inhibits NMDA-activated ion current in hippocampal neurons. Science 243: 1721-1724.

Lowery-Gionta EG, Marcinkiewcz CA, Kash TL. 2015. Functional alterations in the dorsal raphe nucleus following acute and chronic ethanol exposure. Neuropsychopharmacology 40: 590-600.

Lucke C, Heidegger T, Rohner M, Toennes SW, Krivanekova L, Muller-Dahlhaus F, Ziemann U. 2014. Deleterious effects of a low amount of ethanol on LTP-like plasticity in human cortex. Neuropsychopharmacology 39: 1508-1518.

Luscher C, Malenka RC. 2011. Drug-evoked synaptic plasticity in addiction: from molecular changes to circuit remodeling. Neuron 69: 650-663.

Luscher C, Nicoll RA, Malenka RC, Muller D. 2000. Synaptic plasticity and dynamic modulation of the postsynaptic membrane. Nat Neurosci 3: 545-550.

Ma T, Barbee B, Wang X, Wang J. 2017. Alcohol induces input-specific aberrant synaptic plasticity in the rat dorsomedial striatum. Neuropharmacology 123: 46-54.

Ma T, Cheng Y, Roltsch Hellard E, Wang X, Lu J, Gao X, Huang CCY, Wei XY, Ji JY, Wang J. 2018. Bidirectional and long-lasting control of alcohol-seeking behavior by corticostriatal LTP and LTD. Nat Neurosci 21: $373-383$.

MacDougall MJ, Fine A. 2014. The expression of long-term potentiation: reconciling the preists and the postivists. Philos Trans R Soc Lond B Biol Sci 369: 20130135 .

Maffei A. 2011. The many forms and functions of long term plasticity at GABAergic synapses. Neural Plast 2011: 254724.

Mameli M, Luscher C. 2011. Synaptic plasticity and addiction: learning mechanisms gone awry. Neuropharmacology 61: 1052-1059.

Manahan-Vaughan D. 1997. Group 1 and 2 metabotropic glutamate receptors play differential roles in hippocampal long-term depression and long-term potentiation in freely moving rats. J Neurosci 17: 3303-3311.

Manahan-Vaughan D, Braunewell KH. 1999. Novelty acquisition is associated with induction of hippocampal long-term depression. Proc Natl Acad Sci 96: 8739-8744.

Marty VN, Spigelman I. 2012. Long-lasting alterations in membrane properties, $\mathrm{k}(+)$ currents, and glutamatergic synaptic currents of nucleus accumbens medium spiny neurons in a rat model of alcohol dependence. Front Neurosci 6: 86.

Mato S, Robbe D, Puente N, Grandes P, Manzoni OJ. 2005. Presynaptic homeostatic plasticity rescues long-term depression after chronic $\Delta^{9}$-tetrahydrocannabinol exposure. J Neurosci 25: 11619-11627.

McBain CJ, Kauer JA. 2009. Presynaptic plasticity: targeted control of inhibitory networks. Curr Opin Neurobiol 19: 254-262.

McBride WJ, Murphy JM, Ikemoto S. 1999. Localization of brain reinforcement mechanisms: intracranial self-administration and intracranial place-conditioning studies. Behav Brain Res 101: 129-152.

McCool BA. 2011. Ethanol modulation of synaptic plasticity. Neuropharmacology 61: 1097-1108.

McNaughton BL, Barnes CA, Rao G, Baldwin J, Rasmussen M. 1986. Long-term enhancement of hippocampal synaptic transmission and the acquisition of spatial information. J Neurosci 6: 563-571.

Minatohara K, Akiyoshi M, Okuno H. 2015. Role of immediate-early genes in synaptic plasticity and neuronal ensembles underlying the memory trace. Front Mol Neurosci 8: 78.

Morisot N, Ron D. 2017. Alcohol-dependent molecular adaptations of the NMDA receptor system. Genes Brain Behav 16: 139-148.

Mulholland PJ, Hopf FW, Bukiya AN, Martin GE, Liu J, Dopico AM, Bonci A, Treistman SN, Chandler LJ. 2009. Sizing up ethanol-induced plasticity: the role of small and large conductance calcium-activated potassium channels. Alcohol Clin Exp Res 33: 1125-1135.

Nabavi S, Fox R, Proulx CD, Lin JY, Tsien RY, Malinow R. 2014. Engineering a memory with LTD and LTP. Nature 511: 348-352.

Nestler EJ. 2013. Cellular basis of memory for addiction. Dialogues Clin Neurosci 15: 13

Nguyen PV, Woo NH. 2003. Regulation of hippocampal synaptic plasticity by cyclic AMP-dependent protein kinases. Prog Neurobiol 71: 401-437.

Nimitvilai S, Lopez MF, Mulholland PJ, Woodward JJ. 2016. Chronic intermittent ethanol exposure enhances the excitability and synaptic plasticity of lateral orbitofrontal cortex neurons and induces a tolerance to the acute inhibitory actions of ethanol. Neuropsychopharmacology 41: 1112-1127.

Nugent FS, Kauer JA. 2008. LTP of GABAergic synapses in the ventral tegmental area and beyond. J Physiol 586: 1487-1493.

Nugent FS, Penick EC, Kauer JA. 2007. Opioids block long-term potentiation of inhibitory synapses. Nature 446: 1086-1090.

Oliet SH, Malenka RC, Nicoll RA. 1996. Bidirectional control of quantal size by synaptic activity in the hippocampus. Science 271: 1294-1297.

Olsen RW, Spigelman I. 2012. GABAA receptor plasticity in alcohol withdrawal. In Jasper's basic mechanisms of the epilepsies (ed. Noebels JL, Avoli M, Rogawski MA, Olsen RW, Delgado-Escueta AV), National Center for Biotechnology Information (US), NCBI Bookshelf Online Book Version, Bethesda, MD.

O’Tousa D, Grahame N. 2014. Habit formation: implications for alcoholism research. Alcohol 48: 327-335.

Patenaude C, Chapman CA, Bertrand S, Congar P, Lacaille JC. 2003. GABAB receptor- and metabotropic glutamate receptor-dependent cooperative long-term potentiation of rat hippocampal GABAA synaptic transmission. J Physiol 553: 155-167.

Piskorowski RA, Chevaleyre V. 2013. Delta-opioid receptors mediate unique plasticity onto parvalbumin-expressing interneurons in area CA2 of the hippocampus. J Neurosci 33: 14567-14578.

Pitel AL, Beaunieux H, Witkowski T, Vabret F, Guillery-Girard B, Quinette P, Desgranges B, Eustache F. 2007. Genuine episodic memory deficits and executive dysfunctions in alcoholic subjects early in abstinence. Alcohol Clin Exp Res 31: 1169-1178.

Popp RL, Lickteig R, Browning MD, Lovinger DM. 1998. Ethanol sensitivity and subunit composition of NMDA receptors in cultured striatal neurons. Neuropharmacology 37: 45-56.

Poschel B, Manahan-Vaughan D. 2005. Group II mGluR-induced long term depression in the dentate gyrus in vivo is NMDA receptor-independent and does not require protein synthesis. Neuropharmacology 49(Suppl 1): $1-12$.

Puglia MP, Valenzuela CF. 2010. Ethanol acutely inhibits ionotropic glutamate receptor-mediated responses and long-term potentiation in the developing CA1 hippocampus. Alcohol Clin Exp Res 34: 594-606.

Renteria R, Maier EY, Buske TR, Morrisett RA. 2017. Selective alterations of NMDAR function and plasticity in D1 and D2 medium spiny neurons in the nucleus accumbens shell following chronic intermittent ethanol exposure. Neuropharmacology 112: 164-171.

Renteria R, Baltz ET, Gremel CM. 2018a. Chronic alcohol exposure disrupts top-down control over basal ganglia action selection to produce habits. Nat Commun 9: 211.

Renteria R, Buske TR, Morrisett RA. 2018b. Long-term subregion-specific encoding of enhanced ethanol intake by D1DR medium spiny neurons of the nucleus accumbens. Addict Biol 23: 689-698.

Roberto M, Varodayan FP. 2017. Synaptic targets: chronic alcohol actions. Neuropharmacology 122: 85-99. 
Roberto M, Nelson TE, Ur CL, Gruol DL. 2002. Long-term potentiation in the rat hippocampus is reversibly depressed by chronic intermittent ethanol exposure. J Neurophysiol 87: 2385-2397.

Roberto M, Madamba SG, Stouffer DG, Parsons LH, Siggins GR. 2004a. Increased GABA release in the central amygdala of ethanol-dependent rats. J Neurosci 24: 10159-10166.

Roberto M, Schweitzer P, Madamba SG, Stouffer DG, Parsons LH, Siggins GR. $2004 \mathrm{~b}$. Acute and chronic ethanol alter glutamatergic transmission in rat central amygdala: an in vitro and in vivo analysis. J Neurosci 24: $1594-1603$.

Roberto M, Bajo M, Crawford E, Madamba SG, Siggins GR. 2006. Chronic ethanol exposure and protracted abstinence alter NMDA receptors in central amygdala. Neuropsychopharmacology 31: 988-996.

Rogan MT, Staubli UV, LeDoux JE. 1997. AMPA receptor facilitation accelerates fear learning without altering the level of conditioned fear acquired. J Neurosci 17: 5928-5935.

Rozov AV, Valiullina FF, Bolshakov AP. 2017. Mechanisms of long-term plasticity of hippocampal GABAergic synapses. Biochemistry (Mosc) 82: 257-263.

Scofield MD, Heinsbroek JA, Gipson CD, Kupchik YM, Spencer S, Smith AC, Roberts-Wolfe D, Kalivas PW. 2016. The nucleus accumbens: mechanisms of addiction across drug classes reflect the importance of glutamate homeostasis. Pharmacol Rev 68: 816-871.

Simmons DV, Petko AK, Paladini CA. 2017. Differential expression of long-term potentiation among identified inhibitory inputs to dopamine neurons. J Neurophysiol 118: 1998-2008.

Spiga S, Talani G, Mulas G, Licheri V, Fois GR, Muggironi G, Masala N, Cannizzaro C, Biggio G, Sanna E, et al. 2014. Hampered long-term depression and thin spine loss in the nucleus accumbens of ethanol-dependent rats. Proc Natl Acad Sci 111: E3745-E3754.

Stephens DN, Ripley TL, Borlikova G, Schubert M, Albrecht D, Hogarth L, Duka T. 2005. Repeated ethanol exposure and withdrawal impairs human fear conditioning and depresses long-term potentiation in rat amygdala and hippocampus. Biol Psychiatry 58: 392-400.

Stuber GD, Hopf FW, Hahn J, Cho SL, Guillory A, Bonci A. 2008. Voluntary ethanol intake enhances excitatory synaptic strength in the ventral tegmental area. Alcohol Clin Exp Res 32: 1714-1720.

Thinschmidt JS, Walker DW, King MA. 2003. Chronic ethanol treatment reduces the magnitude of hippocampal LTD in the adult rat. Synapse 48: 189-197.

Tipps ME, Raybuck JD, Lattal KM. 2014. Substance abuse, memory, and post-traumatic stress disorder. Neurobiol Learn Mem 112: 87-100.

Turrigiano G. 2012. Homeostatic synaptic plasticity: local and global mechanisms for stabilizing neuronal function. Cold Spring Harb Perspect Biol 4: a005736.

Upreti C, Zhang XL, Alford S, Stanton PK. 2013. Role of presynaptic metabotropic glutamate receptors in the induction of long-term synaptic plasticity of vesicular release. Neuropharmacology 66: 31-39.

Valenzuela CF, Lindquist B, Zamudio-Bulcock PA. 2010. A review of synaptic plasticity at Purkinje neurons with a focus on ethanol-induced cerebellar dysfunction. Int Rev Neurobiol 91: 339-372.

Wang J, Carnicella S, Phamluong K, Jeanblanc J, Ronesi JA, Chaudhri N, Janak PH, Lovinger DM, Ron D. 2007. Ethanol induces long-term facilitation of NR2B-NMDA receptor activity in the dorsal striatum: implications for alcohol drinking behavior. J Neurosci 27: 3593-3602.

Wang J, Lanfranco MF, Gibb SL, Yowell QV, Carnicella S, Ron D. 2010. Long-lasting adaptations of the NR2B-containing NMDA receptors in the dorsomedial striatum play a crucial role in alcohol consumption and relapse. J Neurosci 30: 10187-10198.

Wang J, Lanfranco MF, Gibb SL, Ron D. 2011. Ethanol-mediated long-lasting adaptations of the NR2B-containing NMDA receptors in the dorsomedial striatum. Channels (Austin) 5: 205-209.

Wang J, Ben Hamida S, Darcq E, Zhu W, Gibb SL, Lanfranco MF, Carnicella S, Ron D. 2012. Ethanol-mediated facilitation of AMPA receptor function in the dorsomedial striatum: implications for alcohol drinking behavior. I Neurosci 32: 15124-15132.

Wang J, Cheng Y, Wang X, Roltsch Hellard E, Ma T, Gil H, Ben Hamida S, Ron D. 2015. Alcohol elicits functional and structural plasticity selectively in dopamine D1 receptor-expressing neurons of the dorsomedial striatum. J Neurosci 35: 11634-11643.

Wilcox MV, Cuzon Carlson VC, Sherazee N, Sprow GM, Bock R, Thiele TE, Lovinger DM, Alvarez VA. 2014. Repeated binge-like ethanol drinking alters ethanol drinking patterns and depresses striatal GABAergic transmission. Neuropsychopharmacology 39: 579-594.

Wills TA, Baucum AJ III, Holleran KM, Chen Y, Pasek JG, Delpire E, Tabb DL, Colbran RJ, Winder DG. 2017. Chronic intermittent alcohol disrupts the GluN2B-associated proteome and specifically regulates group I mGlu receptor-dependent long-term depression. Addict Biol 22: 275-290.

Wong TP, Howland JG, Robillard JM, Ge Y, Yu W, Titterness AK, Brebner K, Liu L, Weinberg J, Christie BR, et al. 2007. Hippocampal long-term depression mediates acute stress-induced spatial memory retrieval impairment. Proc Natl Acad Sci 104: 11471-11476.

Xia JX, Li J, Zhou R, Zhang XH, Ge YB, Ru Yuan X. 2006. Alterations of rat corticostriatal synaptic plasticity after chronic ethanol exposure and withdrawal. Alcohol Clin Exp Res 30: 819-824.

Yang Y, Calakos N. 2013. Presynaptic long-term plasticity. Front Synaptic Neurosci 5: 8.

Yeckel MF, Kapur A, Johnston D. 1999. Multiple forms of LTP in hippocampal CA3 neurons use a common postsynaptic mechanism. Nat Neurosci 2: 625-633.

Yin HH, Knowlton BJ. 2006. The role of the basal ganglia in habit formation. Nat Rev Neurosci 7: 464-476.

Yin HH, Davis MI, Ronesi JA, Lovinger DM. 2006. The role of protein synthesis in striatal long-term depression. J Neurosci 26: 11811-11820.

Yin HH, Park BS, Adermark L, Lovinger DM. 2007. Ethanol reverses the direction of long-term synaptic plasticity in the dorsomedial striatum. Eur J Neurosci 25: 3226-3232.

Younts TJ, Monday HR, Dudok B, Klein ME, Jordan BA, Katona I, Castillo PE. 2016. Presynaptic protein synthesis is required for long-term plasticity of GABA release. Neuron 92: 479-492.

Zhu PJ, Lovinger DM. 2007. Persistent synaptic activity produces long-lasting enhancement of endocannabinoid modulation and alters long-term synaptic plasticity. J Neurophysiol 97: 4386-4389.

Zhu W, Bie B, Pan ZZ. 2007. Involvement of non-NMDA glutamate receptors in central amygdala in synaptic actions of ethanol and ethanol-induced reward behavior. J Neurosci 27: 289-298.

Zorumski CF, Mennerick S, Izumi Y. 2014. Acute and chronic effects of ethanol on learning-related synaptic plasticity. Alcohol 48: 1-17.

Zucker RS, Regehr WG. 2002. Short-term synaptic plasticity. Апnи Rev Physiol 64: 355-405.

Received March 29, 2018; accepted in revised form June 21, 2018. 


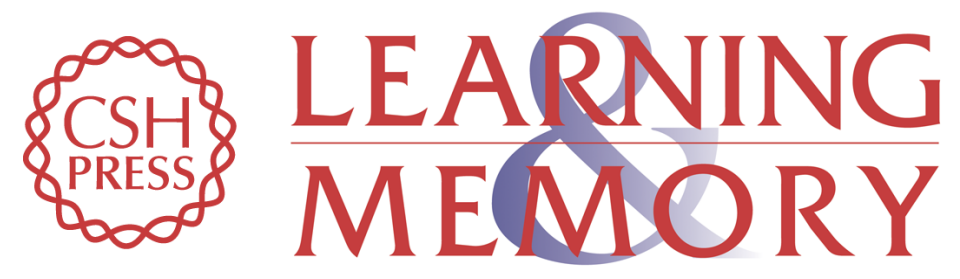

\section{Synaptic plasticity mechanisms common to learning and alcohol use disorder}

David M. Lovinger and Karina P. Abrahao

Learn. Mem. 2018, 25:

Access the most recent version at doi:10.1101/Im.046722.117

References This article cites 158 articles, 37 of which can be accessed free at: http://learnmem.cshlp.org/content/25/9/425.full.html\#ref-list-1

License This is a work of the US Government.

Email Alerting Receive free email alerts when new articles cite this article - sign up in the box at the Service top right corner of the article or click here. 